\title{
RESPIRATORY SENSATIONS IN PATIENTS WITH CERVICAL CORD TRANSECTION
}

By H. L. Frankel, M.B., M.R.C.P., A. GuZ, M.D., F.R.C.P., and

M. Noble, M.D., Ph.D., B.Sc., M.R.C.P.

National Spinal Injuries Centre, Stoke Mandeville Hospital and

Charing Cross Hospital, London

\section{INTRODUCTION}

DYSPNOEIC patients usually give descriptions of feelings arising in the chest. We have been interested to discover whether any of these sensations arise from different nervous impulses coming from the chest wall, diaphragm or intrathoracic organs. Patients with low cervical cord transection have interruption of nerve pathways from the chest wall and patients with high cervical cord transection have no afferent pathways from the chest wall or diaphragm to the brain. They are, therefore, an interesting group of patients to question about respiratory sensations.

\section{MATERIAL}

Eight patients with low cervical cord transection (complete below $\mathrm{C}_{5}-\mathrm{C}_{7}$ ) were studied. T. S., male aged 22, J. B., male aged 27, R. B., male aged 34, S. I., male aged 46, T. M., male aged 28 , P. S., male aged 20 , S. S., male aged 45 and R. H., male aged 26. All the studies were carried out when the patients were well and adequate diaphragmatic ventilation being maintained.

One patient with high cervical cord transection was studied. R. A., male aged 24, was studied on several occasions during the third year following a fracture dislocation of the second and third cervical vertebrae ( $\mathrm{C}_{3}$ lesion). He was well and adequate ventilation $=\left(\mathrm{PET}_{2} 35 \mathrm{~mm}\right.$. $\mathrm{Hg}$. vital capacity $860 \mathrm{ml}$.) was maintained by his greatly hypertrophied sternomastoid muscles. The diaphragm showed no activity as judged by clinical, fluoroscopic and electromyographic criteria. A tracheostomy was present.

\section{PROCEDURES}

Breath Holding. The patients were asked to hold their breath at the end of a normal expiration and to continue breath holding as long as possible. Their description of the sensation produced by this manoeuvre was then noted. In order to try and prevent hypoxia during the breath hold, Ioo per cent. oxygen was administered for Io min. prior to breath holding.

In patient $\mathrm{R}$. A. electromyographic recordings were made from the diaphragm by means of an oesophageal electrode and from the sterno-mastoid by means of surface electrodes (Noble et al., I971 $a$ ).

Detection of Added Resistance. The patient R. A. was blindfolded and the cuff of his tracheotomy tube was inflated; his tracheotomy tube was connected to a tube which contained a series of known linear resistances (Noble et al., 1970, Noble et al., 197I $b$ ). The patient was asked to signal when he felt he was breathing 
through any added resistance. A percentage detection score was obtained in the manner described by Bennett et al. (I962).

\section{RESULTS}

The breath holding times ranged from 2I sec. to I 7I sec. and are thus within the normal range. The longest breath holding time was I7I sec. in R. A., the patient with the $\mathrm{C}_{3}$ lesion. The replies to the question regarding holding sensation were as follows: T. S., 'a pressure round the diaphragm', J. B., 'uncomfortable,

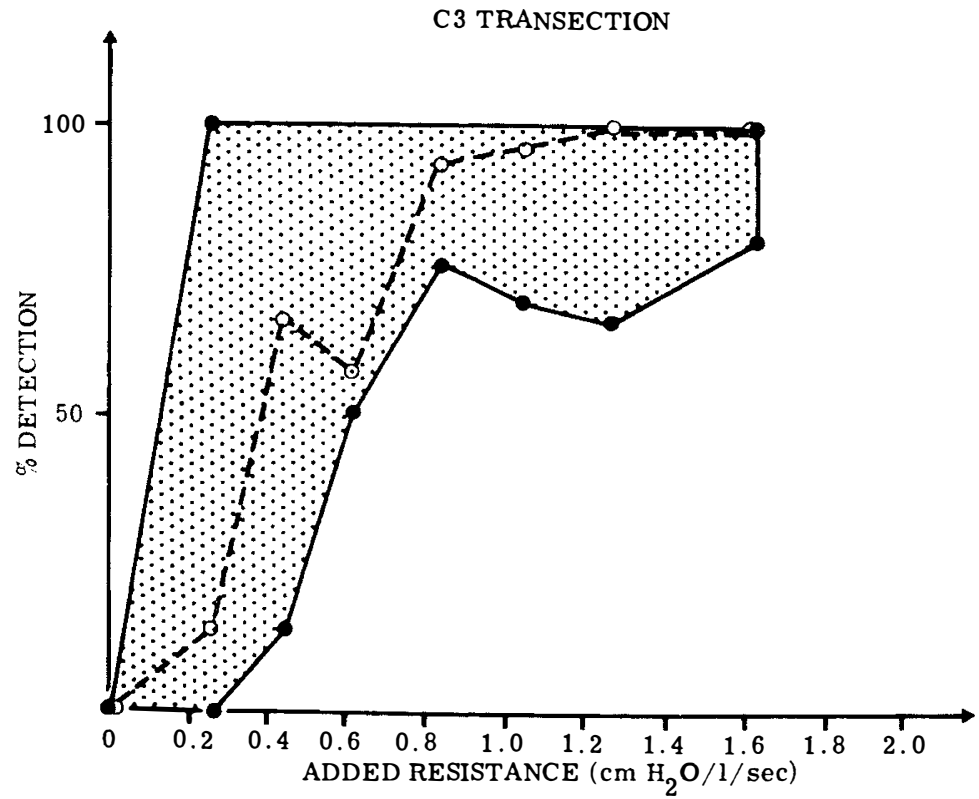

Ordinate $=$ per cent. detection (each load was presented six times and 5 points awarded for detection on the first breath, 4 points on the second etc. Maximum score of $30=100$ per cent.) Abscissa $=$ magnitude of added resistive load. Stippled area = range for normal mouth breathing subjects. Dashed line $=$ result in patient $\mathrm{R}$. A. breathing through a cuffed tracheotomy tube.

even painful in the lower chest', R. B., 'a need for air in the throat and a feeling in the tummy', S. I. 'saliva in the throat', T. M., 'discomfort in the upper abdomen and in the lower chest', P. S., 'a force moving in the upper abdomen', S. S., 'a feeling in the tummy', R. H., 'wanted to burst in the chest and upper abdomen'. These replies are similar to those obtained in normal subjects. In all these patients diaphragmatic contractions occurred during breath holding, producing abdominal movements in an otherwise completely paralysed trunk. The reply of R. A. was 'things started to go black'. He made no mention of sensation in the throat, chest or abdomen until specifically asked. He then denied any sensation from these areas. The diaphragm did not contract during breath holding (E.M.G. silence), but sternomastoid activity was present. 
The ability of R. A. to detect resistances added to his airway was completely within the normal range (see figure).

\section{DISCUSSION}

If a normal subject holds his breath in the manner described (under 'Procedure' above) and, at the break point, inspires an asphyxial gas mixture, his discomfort is relieved and further breath holding is possible despite the greater asphyxia (Fowler, 1954). This shows that the sensation is not due to asphyxia. Furthermore, the relief occurs during the first breath of the asphyxial gas suggesting that a nervous reflex is involved.

The fact that breath holding sensation was apparently normal in the patients with low cervical cord transection (chest wall paralysed) suggests that the chest wall is not involved. The lack of the usual sensation in R. A. (diaphragm paralysed as well) suggests that the diaphragm is involved in the genesis of this sensation. These results are in agreement with the facts that $(a)$ breath holding sensation is relieved and breath holding time prolonged by total muscular paralysis (Campbell et al., 1967), (b) there is no effect of spinal anaesthesia raised to the level of TI (Eisele et al., I 968) but that (c) phrenic block relieves the sensation and prolongs breath holding time (Noble et al., 1970). It has also been shown that the 'drive to breathe' during breath holding depends on afferent vagal fibres (Noble et al. 1970). This 'drive to breathe' was present in R. A. and manifested by rhythmic discharges in the sternomastoid E.M.G. The fact that the patient did not feel the usual sensation shows that it is not the drive itself which is appreciated by consciousness, but the consequent contractions of the diaphragm (and only the diaphragm).

The ability to detect resistive loads added at the mouth is mainly dependent on receptors in the mouth and upper airways (Novle et al., 1970). In order to study thoracic mechanisms it is therefore necessary to add the resistances to the trachea directly. The fact that $\mathbf{R}$. A. had normal detection of resistances added in this way shows that the chest wall and diaphragm are not necessarily involved in the genesis of the sensation by means of which such loads are detected. Since this patient's vagi were intact it is presumed that the necessary information reached the brain by this route, possibly following stimulation of receptors in the airways due to a change in airway pressure.

The relevance of these observations to clinical dyspnoea remains uncertain. Careful observation of symptoms in patients with cervical cord transection who suffer pulmonary embolism, pneumonia, etc., will be needed to probe this question further.

\section{REFERENCES}

Bennett, E. D., Jayson, M. I. V., Rubinstein, D. \& Campbell, E. J. M. (I962). Clinical Science, 23, I55.

Campbell, E. J. M., Freedman, S., Clark, T. J. H., Robson, J. G. \& Normal, J. (I967). Clinical Science, 32, 425.

Eisele, J., Trenchard, D., Burki, N. \& Guz, A. (I968). Clinical Science, 35, 23.

Fowler, W. S. (1954). F. Appl. Physiol., 6, 539.

Noble, M. I. M., EISELE, J. H., TRENCHARD, D. \& Guz, A. (1970). Breathing: HeringBreuer Centenary Symposium. Ciba Foundation Symposium. London: J. and A. Churchill. 
Noble, M. I. M., Eisele, J. H., Frankel, H. L., Else, Wendy \& Guz, A. (I97I a). Clinical Science, 4I, 275.

Noble, M. I. M., Frankel, H. L., Else, Wendy \& Guz, A. (I971b). Clinical Science, 4I, 285.

\section{SUMMARY}

The sensation of breath holding and the ability to detect added external respiratory resistance was investigated in nine patients with complete cervical cord lesions. (Eight patients with lesions between $\mathrm{C}_{5}$ and $\mathrm{C}_{7}$ and one patient with a complete lesion below $\mathrm{C}_{3}$.)

All the patients could detect added resistive loads normally. All the patients except the one with the $\mathrm{C}_{3}$ lesion had normal sensations of breath holding.

It is concluded that the information about pressure changes reached consciousness via the vagi and that the sensation of breath holding is dependent on contractions of the diaphragm.

\section{RÉSUMÉ}

La sensation de retenir la respiration et la capacité à détecter un supplément de résistance respiratoire externe ont été détectées parmi 9 patients ayant tous des lésions médullaires cervicales complètes ( 8 patients avec des lésions entre $\mathrm{C}_{5}$ et $\mathrm{C}_{7}$ et un patient avec une lésion en-dessous de $\mathrm{C}_{3}$ ).

Tous les patients ont pu détecter normalement une charge respiratoire additionnelle. Tous les patients excepté celui avec une lésion en $C_{3}$, avaient des sensations normales pour retenir la respiration.

On a conclu que les informations de changement de pression atteignent la conscience par le nerf vague et que la sensation de retenir sa respiration est dépendante des contractions du diaphragme.

\section{ZUSAMMENFASSUNG}

Die Sensation als Folge von Anhalten der Atmung und die Fähigkeit, den additionellen äusseren respiratorischen Widerstand zu entdecken, wurde an 9 completten Tetraplegikern gemessen ( 8 mit $\mathrm{C}_{5}$ und $\mathrm{C}_{7}$ Läsionen und I unterhalb $\mathrm{C}_{3}$ ).

Alle Patienten konnten normal vermehrten Widerstand fühlen und alle mit Ausnahme der $\mathrm{C}_{3}$ Läsion hatten normale Sensationen des Anhalten der Atmung.

Es wird angenommen, dass de Information über Druckveränderungen erreicht das Bewusstsein über den Vagus, während die Sensation nach Anhalten der Atmung von der Kontraction des Zwerchfells abhängt.

\section{Discussion}

Sir Ludwig GutTManN (G.B.). This was another series of interesting papers on the physiology and patho-physiology of the autonomic system. You saw in the film how by inspiration the sternomastoid contracted and the antero-posterior diameter of the thorax moved upwards. And that is of greatest importance in the treatment of tetraplegics from the beginning to develop the action of the auxiliary respiratory muscles-the trapezius and sternomastoid. This is a life-saving measure, because these are the only muscles left which can compensate for the paralysis of the intercostals, and the sooner you tell the physiotherapist to concentrate on their maximal function it will save the lives of these people and you might render tracheostomies unnecessary. I would say it is unfortunate that people rush into tracheostomy too early. We have heard previously from Dr. Dollfus and Dr. Frankel about the undesirable reflexes that may occur following this procedure. The papers of Dr. Hallin and Dr. Silver and Dr. Noble and his colleagues are really good coordination of the function of the respiratory system.

P. HARRIS (G.B.). I would like to ask Dr Noble if he has some special idea about the situation in the patient with a cervical spinal lesion who may forget to breathe. This, 